\title{
Analysis of manifestation of joint acoustic and electric re- sponses of near-surface sedimentary rocks on the defor- mation by earthquake seismic waves in the South of Kam- chatka
}

\author{
Mikhail Mishchenko ${ }^{1, *}$, Oleg Rulenko ${ }^{2}$, and Yuriy Marapulets ${ }^{1}$ \\ ${ }^{1}$ Institute of Cosmophysical Research and Radio Wave Propagation FEB RAS, Mirnaya, 7, Paratunka, \\ Kamchatkskiy kray, 684034, Russia \\ ${ }^{2}$ Institute of Volcanology and Seismology FEB RAS, bul'var Piypa, 9, Petropavlovsk-Kamchatskiy, \\ 683006, Russia
}

\begin{abstract}
We continue the investigation of earlier discovered joint acoustic and electric responses of near-surface sedimentary rocks on the deformation by earthquake seismic waves. The appearance and absence of this response in earthquakes with the energy class of more than 11.0, which occurred from June 2017 to May 2021 by the eastern coast of Kamchatka in the latitude band of 51.7-54. $0^{\circ} \mathrm{N}$, are under consideration. From those earthquakes we selected 52 events, the seismic waves of which had rock acoustic response at Karymshina site, IKIR FEB RAS. Occurrences of joint acoustic and electric responses of rocks and manifestations of their low-frequency and high-frequency acoustic responses were analyzed. Applying the nonparametric correlation Spearman analysis, statistically significant relation between the energy class of the earthquakes under consideration and the distance from hypocenter to the observation site was discovered.
\end{abstract}

\section{Introduction}

Transmission of seismic waves, generated by earthquake sources, causes rock deformation and is accompanied by different co-seismic effects [1]. These effects can manifest strongly enough as long as rock deformation occurs with the rate higher than that during the background regime. Among them, seismoelectric effect of the second kind [2] and geoacoustic effect [3], observed in sedimentary rocks, are known.

Disturbances of geoelectric and geoacoustic fields occurring during seismic wave transmission though the near-surface sedimentary rocks have their own features of genesis but common deformation nature. Joint seismoelectric and seismoacoustic responses of these rocks were firstly discovered in 2018 at Karymshina site of IKIR FEB RAS [4]. Investigation of these responses was continued in 2019-2020 [5, 6].

Based on drilling results, the near-surface rocks at the observation site region are sedimentary with the layer thickness of about $50 \mathrm{~m}$ [7]. The distance between the electrodes for geoelectric signal recording is $10 \mathrm{~m}$ and the depth of electrodes in the ground is $1 \mathrm{~m}$.

\footnotetext{
*e-mail: micle@ikir.ru
} 
According to the estimates in the paper [3], the sources of acoustic signals, generated in sedimentary rocks at the frequencies from the first hundreds of hertz to the first tens of kilohertz, are located at the distances up to $37 \mathrm{~m}$ from the hydrophone. Taking all that into account, we can say that the observed seismoelectric and seismoacoustic signals occur in the near-surface sedimentary rocks having the volume up to $10^{5} \mathrm{~m}^{3}$. This volume of rocks can be considered as two operating simultaneously natural seismometer, that transform the seismic wave energy into the energy of electric and acoustic signal.

In the previous investigations we considered the features of manifestation of joint seismoelectric and seismoacoustic responses for five [5] and six [6] earthquakes of different energy, which occurred in Kamchatka region. In the paper, 52 earthquakes of this region are considered during the investigation of such responses.

\section{Analysis and results}

Initial data. Seismoacoustic and seismoelectric observations were carried out at Karymshina site $\left(52.83^{\circ} \mathrm{N}, 158.13^{\circ} \mathrm{E}\right)$ of IKIR FEB RAS. The observation method and the applied measuring-recording complex are described in the papers $[4,5]$. To analyze the manifestation of rock joint response, we considered the earthquakes with the energy class $K_{s}>11.0$. They occurred from June 2017 to May 2021 by the eastern coast of South Kamchatka in the latitude band of 51.7-54.0 $0^{\circ}$. Only those earthquakes were chosen, in which there was necessarily low-frequency, approximately $100 \mathrm{~Hz}$, seismoacoustic response, since at the same distance from the hypocenter it occurs with weaker earthquakes than the seismoelectric response. The parameters of these earthquakes are taken from the catalogue of Kamchatka Branch of Geophysical Survey RAS (http://sdis.emsd.ru/info/earthquakes/catalogue.php) and are illustrated in Table 1.

Table 1. Earthquake parameters based on which the manifestation of seismoacoustic and seismoelectric responses of near-surface sedimentary rock on the deformation by seismic waves were analyzed; $K_{s}$ is the earthquake energy class; $D$ is the hypocentral distance to Karymshina site; $A$ is the presence of joint seismoacoustic and seismoelectric responses of rocks $(\downarrow)$ or only their seismoacoustic response $(\bigcirc)$; $B$ is the presence of low-, mid- and high-frequency clusters ( $\bullet$ ) or only of low-frequency cluster $(\bigcirc)$ in seismoacoustic response

\begin{tabular}{|c|c|c|c|c|c|c|c|c|c|}
\hline \multirow{2}{*}{ No. } & \multicolumn{2}{|c|}{ Earthquake } & \multicolumn{2}{|c|}{$\begin{array}{c}\text { Epicenter } \\
\text { coordinates }\end{array}$} & \multirow[t]{2}{*}{$H, \mathrm{~km}$} & \multirow[t]{2}{*}{$K_{s}$} & \multirow[t]{2}{*}{$D, \mathrm{~km}$} & \multirow[t]{2}{*}{$A$} & \multirow[t]{2}{*}{$B$} \\
\hline & $\begin{array}{l}\text { Date, } \\
\text { UTC }\end{array}$ & $\begin{array}{l}\text { Time, } \\
\text { UTC }\end{array}$ & Lat. $^{\circ} \mathrm{N}$ & Long. ${ }^{\circ} \mathrm{E}$ & & & & & \\
\hline 1 & 2017.06.27 & $02: 23: 18.1$ & 52.58 & 160.80 & 40 & 12.1 & 186 & 0 & 0 \\
\hline 2 & 2017.07 .06 & $23: 02: 46.3$ & 53.26 & 160.77 & 49 & 12.4 & 189 & 0 & 0 \\
\hline 3 & 2017.07 .25 & $16: 24: 51.5$ & 53.85 & 159.74 & 124 & 11.1 & 199 & 0 & 0 \\
\hline 4 & 2017.08 .02 & $21: 05: 39.1$ & 53.08 & 160.09 & 61 & 11.8 & 147 & 0 & 0 \\
\hline 5 & 2017.08 .19 & $00: 59: 56.4$ & 52.90 & 160.25 & 87 & 11.1 & 167 & 0 & 0 \\
\hline 6 & 2017.09 .15 & $17: 26: 11.2$ & 53.71 & 160.86 & 59 & 11.3 & 214 & 0 & 0 \\
\hline 7 & 2017.09 .16 & 21:00:54.7 & 52.82 & 160.00 & 53 & 12.8 & 136 & $\bullet$ & $\downarrow$ \\
\hline 8 & 2017.09 .18 & $01: 23: 30.8$ & 53.15 & 159.70 & 76 & 11.3 & 134 & 0 & 0 \\
\hline 9 & 2017.09 .29 & 19:24:59.1 & 53.10 & 160.33 & 51 & 13.4 & 159 & $\bullet$ & 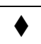 \\
\hline 10 & 2017.10 .10 & $22: 59: 22.2$ & 51.96 & 159.62 & 45 & 11.8 & 146 & 0 & 0 \\
\hline 11 & 2017.12 .02 & $15: 11: 38.1$ & 52.54 & 159.88 & 44 & 11.3 & 130 & 0 & 0 \\
\hline 12 & 2017.12.05 & 09:06:03.0 & 53.70 & 161.13 & 44 & 11.3 & 226 & 0 & 0 \\
\hline 13 & 2017.12 .22 & $14: 44: 16.2$ & 53.68 & 160.88 & 69 & 14.2 & 217 & $\bullet$ & 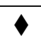 \\
\hline 14 & 2017.12 .22 & $15: 36: 33.1$ & 53.69 & 160.87 & 53 & 11.2 & 212 & 0 & 0 \\
\hline
\end{tabular}


Continuation of Table 1.

\begin{tabular}{|c|c|c|c|c|c|c|c|c|c|}
\hline \multirow{2}{*}{ No. } & \multicolumn{2}{|c|}{ Earthquake } & \multicolumn{2}{|c|}{$\begin{array}{l}\text { Epicenter } \\
\text { coordinates }\end{array}$} & \multirow[t]{2}{*}{$H, \mathrm{~km}$} & \multirow[t]{2}{*}{$K_{s}$} & \multirow[t]{2}{*}{$D, \mathrm{~km}$} & \multirow[t]{2}{*}{$A$} & \multirow[t]{2}{*}{$B$} \\
\hline & $\begin{array}{l}\text { Date, } \\
\text { UTC }\end{array}$ & $\begin{array}{l}\text { Time, } \\
\text { UTC }\end{array}$ & Lat. $^{\circ} \mathrm{N}$ & Long. ${ }^{\circ} \mathrm{E}$ & & & & & \\
\hline 15 & 2017.12 .22 & $22: 28: 22.6$ & 53.72 & 160.78 & 61 & 12.4 & 211 & 0 & 0 \\
\hline 16 & 2018.01 .04 & $02: 44: 54.4$ & 53.12 & 160.20 & 56 & 12.9 & 153 & 0 & 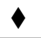 \\
\hline 17 & 2018.01 .14 & 14:04:50.3 & 52.72 & 159.88 & 50 & 11.3 & 128 & 0 & 0 \\
\hline 18 & 2018.01 .17 & 18:58:04.6 & 53.13 & 160.99 & 52 & 11.2 & 201 & 0 & 0 \\
\hline 19 & 2018.03 .05 & $15: 42: 41.0$ & 52.38 & 160.80 & 48 & 13.1 & 193 & 0 & 0 \\
\hline 20 & 2018.04 .06 & $16: 13: 13.0$ & 52.45 & 159.17 & 86 & 11.5 & 119 & 0 & 0 \\
\hline 21 & 2018.07.21 & $04: 19: 16.7$ & 51.73 & 159.40 & 36 & 12.3 & 153 & 0 & 0 \\
\hline 22 & 2018.10 .15 & 01:32:11.1 & 53.95 & 159.86 & 125 & 12.8 & 210 & 0 & 0 \\
\hline 23 & 2018.11 .02 & $09: 39: 27.7$ & 51.98 & 158.72 & 72 & 13.1 & 125 & $\bullet$ & 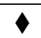 \\
\hline 24 & 2019.01 .03 & $17: 57: 43.5$ & 53.14 & 160.05 & 58 & 12.2 & 145 & $\bullet$ & 0 \\
\hline 25 & 2019.01 .12 & 11:18:58.4 & 52.79 & 159.80 & 60 & 12.4 & 127 & $\bullet$ & 0 \\
\hline 26 & 2019.02 .08 & 17:08:35.2 & 52.42 & 159.05 & 59 & 12.0 & 97 & $\bullet$ & 0 \\
\hline 27 & 2019.02 .14 & $18: 24: 27.6$ & 52.39 & 159.13 & 58 & 11.2 & 101 & $\bullet$ & 0 \\
\hline 28 & 2019.04 .16 & $15: 22: 50.8$ & 53.69 & 160.94 & 55 & 12.1 & 217 & 0 & 0 \\
\hline 29 & 2019.07 .18 & $12: 45: 38.6$ & 52.43 & 159.99 & 51 & 11.8 & 142 & $\bullet$ & 0 \\
\hline 30 & 2019.07 .28 & 09:53:04.0 & 53.70 & 160.88 & 52 & 11.5 & 213 & 0 & 0 \\
\hline 31 & 2019.07.31 & $12: 56: 36.9$ & 52.36 & 159.81 & 47 & 11.1 & 133 & 0 & 0 \\
\hline 32 & 2019.09 .23 & $21: 54: 55.9$ & 52.01 & 159.93 & 21 & 11.8 & 153 & 0 & 0 \\
\hline 33 & 2019.10 .05 & $16: 18: 36.6$ & 51.69 & 158.89 & 63 & 11.4 & 150 & 0 & 0 \\
\hline 34 & 2019.11 .09 & $11: 16: 57.2$ & 52.33 & 161.05 & 54 & 11.6 & 212 & 0 & 0 \\
\hline 35 & 2020.01 .01 & 03:53:26.2 & 52.50 & 159.40 & 46 & 12.4 & 104 & $\bullet$ & $\bullet$ \\
\hline 36 & 2020.01 .16 & $16: 31: 09.5$ & 52.01 & 159.84 & 29 & 12.8 & 150 & $\bullet$ & $\checkmark$ \\
\hline 37 & 2020.01 .16 & $21: 50: 56.4$ & 51.98 & 159.93 & 30 & 11.1 & 157 & 0 & 0 \\
\hline 38 & 2020.01 .28 & $04: 19: 45.8$ & 52.40 & 159.56 & 47 & 11.5 & 117 & $\bullet$ & 0 \\
\hline 39 & 2020.02 .20 & $18: 57: 34.4$ & 53.44 & 160.92 & 52 & 14.3 & 205 & $\bullet$ & $\checkmark$ \\
\hline 40 & 2020.03 .12 & 05:20:10.0 & 52.40 & 159.11 & 56 & 12.2 & 99 & $\bullet$ & 0 \\
\hline 41 & 2020.05 .17 & $19: 26: 31.5$ & 52.02 & 159.98 & 42 & 11.4 & 160 & 0 & 0 \\
\hline 42 & 2020.05 .30 & 11:01:32.1 & 52.83 & 159.40 & 115 & 11.9 & 143 & 0 & 0 \\
\hline 43 & 2020.08 .07 & 03:41:09.3 & 52.20 & 159.27 & 63 & 12.0 & 121 & $\bullet$ & 0 \\
\hline 44 & 2020.08 .25 & $21: 53: 43.7$ & 52.86 & 160.24 & 50 & 11.4 & 150 & 0 & 0 \\
\hline 45 & 2020.09 .04 & 21:10:12.9 & 52.08 & 160.56 & 49 & 12.7 & 190 & 0 & 0 \\
\hline 46 & 2020.09 .04 & $21: 14: 22.3$ & 52.08 & 160.43 & 18 & 11.8 & 177 & 0 & 0 \\
\hline 47 & 2020.09 .05 & $00: 21: 21.0$ & 52.09 & 160.59 & 46 & 11.8 & 191 & 0 & 0 \\
\hline 48 & 2020.10 .05 & 09:04:29.8 & 52.22 & 158.98 & 100 & 11.5 & 133 & 0 & 0 \\
\hline 49 & 2020.11 .27 & $22: 57: 13.1$ & 52.04 & 159.98 & 40 & 11.8 & 158 & 0 & 0 \\
\hline 50 & 2021.01 .11 & $12: 56: 39.3$ & 52.46 & 159.22 & 61 & 11.4 & 104 & $\bullet$ & 0 \\
\hline 51 & 2021.04 .11 & $13: 48: 49.0$ & 52.08 & 158.88 & 60 & 11.9 & 114 & $\bullet$ & 0 \\
\hline 52 & 2021.05 .05 & $14: 08: 42.4$ & 51.98 & 159.19 & 66 & 11.2 & 135 & $\bullet$ & 0 \\
\hline
\end{tabular}

Manifestation of joint acoustic and electric response of rocks. Fig. 1a shows the map of the considered earthquake (Table 1) epicenters and Karymshina site location. It shows the earthquakes in different ways, because during seismic wave transmission either joint acoustic and electric responses of rocks or only their acoustic response were observed. As the result, two groups of earthquakes were obtained. Using the same symbols, Fig. 1b illustrates comparison of their energy classes $K_{s}$ and the hypocentral distances $D$ to Karymshina site. To consider the relation between $K_{s}$ and $D$, nonparametric correlation analysis was used in two 
selected groups. Rank correlation Spearman coefficient $r_{s}$ was considered. It is less sensitive to any jumps and errors in observation results. Moreover, it allows us to estimate monotonous nonlinear relations between the variables and can be used for small sampling volumes [8] that is topical in our case.

Table 2 (Fig. 1b) shows the estimates of correlation coefficient $r_{s}$ and its significance level $p$ between $K_{s}$ and $D$ for the two groups of earthquakes illustrated in Fig. 1a. It is clear from Table 2 , there is a statistically significant relation $\left(r_{s}=0.597, p=0.009\right)$ between the energy class of earthquakes, during which joint seismoacoustic and seismoelectric responses of rocks were observed, and hypocentral distance $D$. Despite of a large sampling volume, there is no such a relation for the earthquakes during which only seismoacoustic response of rocks $\left(r_{s}=0.129, p=0.468\right)$ was observed.

Manifestation of high-frequency acoustic response of rocks. It was discovered in the papers [4-6] that during the transmission of seismic waves from strong and relatively close earthquakes, rock acoustic response can appear at the frequencies of $\sim 0.1-1 \mathrm{kHz}$ and even $\sim 1-11 \mathrm{kHz}$ in addition to the low-frequency response up to about $100 \mathrm{~Hz}$. Occurrences of these two higher-frequency, compared to seismic wave frequency, clusters were recorded during $P$-wave passage from a strong and close Zhupanovskoe earthquake on January 30, 2016 $\left(M_{w}=7.2, D=220 \mathrm{~km}\right)$ [4]. Occurrence of the cluster was observed only at the frequencies of $\sim 0.1-1 \mathrm{kHz}$ during $P$-wave passage from a strong but more remote earthquake on March $35,2020\left(M_{w}=7.5, D=434 \mathrm{~km}\right)[6]$.

Fig. 2a, just like Fig. 1a, shows a map of the considered earthquake epicenters, and Fig. 2b illustrates the comparison of their energy classes $K_{s}$ and hypocentral distances $D$ to Karymshina site. Taking into the consideration the possibility of occurrence of higherfrequency clusters in the seismoacoustic response of rocks, all earthquakes were divided into two groups. First group included those, during which only low-frequency cluster up to about $100 \mathrm{~Hz}$ was observed in rock seismoacoustic response. Other group contained the earthquakes, during which besides that cluster, a mid-frequency cluster at the frequencies of $\sim 0.1-1 \mathrm{kHz}$ and even high-frequency cluster at the frequencies of $\sim 1-11 \mathrm{kHz}$ were observed in the seismoacoustic response. The results for the analysis of the relation between $K_{s}$ and $D$ for the cases of high-frequency acoustic cluster occurrences in rock seismoacoustic response and the cases of their absence are illustrated in Table 2 (Fig. 2b).

It is clear from Table 2 (Fig. 2b), there is statistically significant relation between $K_{s}$ and $D\left(r_{s}=0.826, p=0.017\right)$ for the earthquakes, during which besides the low-frequency cluster in the seismoacoustic response, mid-frequency and even high-frequency clusters are presented. The authors [5] think that occurrences of these two clusters indicate the transformation of rock low-frequency seismic wave energy into higher-frequency energy of acoustic signals. Such a transformation is likely to occur during intensive deformations of sedimentary rocks, formation of relative microdisplacements and interactions of small fragments. Based on the results from Table 2 (Fig. 2b), there is no correlation relation between $K_{s}$ and $D$ $\left(r_{s}=0.031, p=0.841\right)$ for the earthquakes, during which only low-frequency cluster was presented in the seismoacoustic response.

We call attention to the statistically significant relation between $K_{s}$ and $D$. The relation was discovered for a small number of earthquakes during which mid-frequency and even high-frequency clusters appeared in the seismoacoustic response (Table 2, Fig. 2b, $r_{s}=0.826$, $p=0.017$ ). However, if the dependence between the variables in a population is strong, it can be detected with high level of significance event on a very small sampling [8], that can, probably, be applied to our case. 


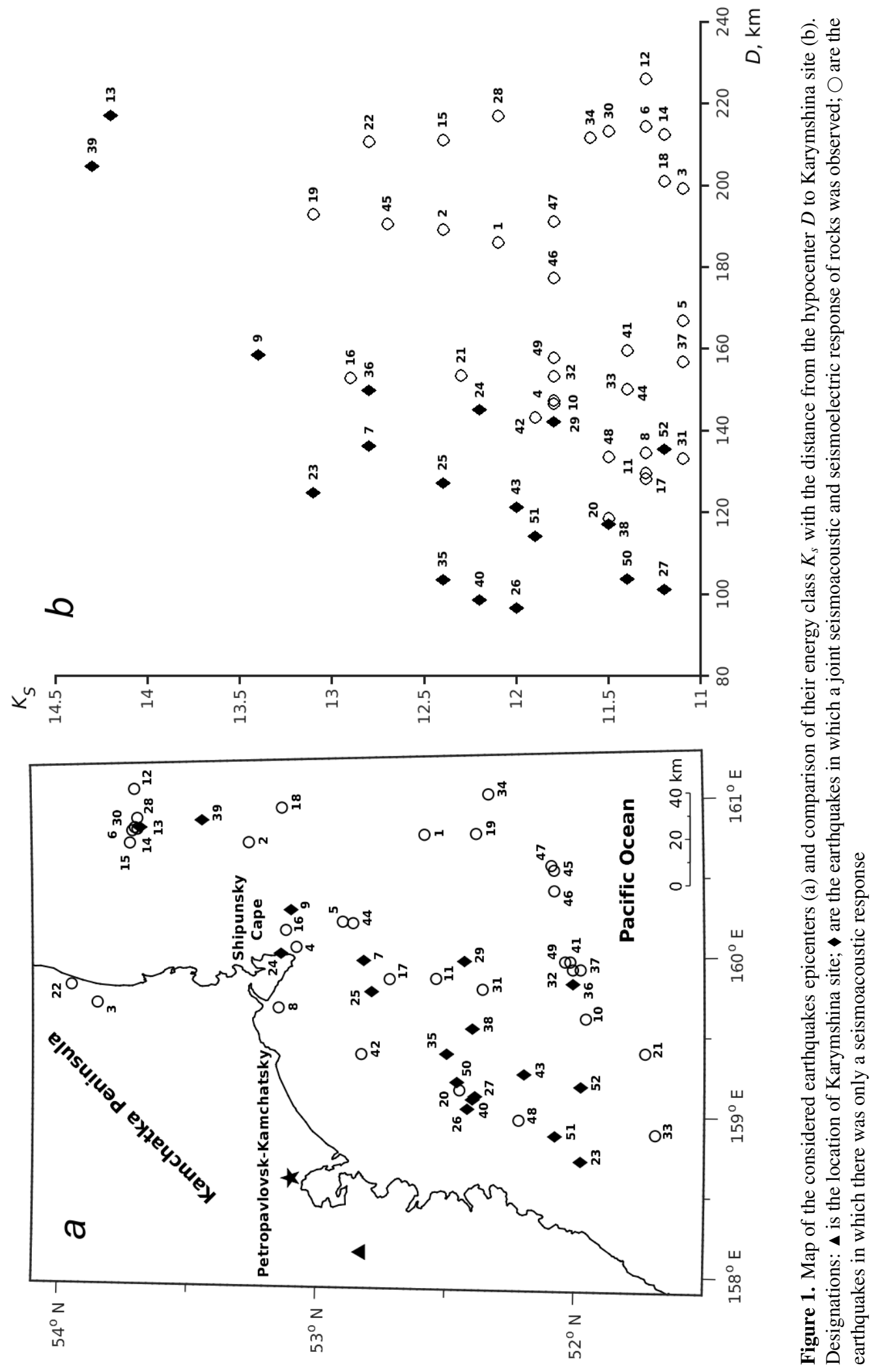







Table 2. Estimates of correlation Spearman coefficient $r_{s}$ and its significance level $p$ between earthquake energy class $K_{s}$ and distance from a hypocenter $D$ to Karymshina site for each group of the detected earthquakes, $n$ is the number of earthquakes in a group. Symbols $(\downarrow)$ and $(\bigcirc)$ are the same as for Table 1 .

\begin{tabular}{|c|c|c|c|c|}
\hline \multirow{2}{*}{ Parameter } & \multicolumn{3}{|c|}{ Earthquake designation in figures } \\
\cline { 2 - 5 } & \multicolumn{2}{|c|}{ Fig. 1b } & \multicolumn{2}{c|}{ Fig. 2b } \\
\cline { 2 - 5 } & $\bullet$ & $\bigcirc$ & $\bullet$ & $\bigcirc$ \\
\hline$r_{s}$ & 0.597 & 0.129 & 0.826 & 0.031 \\
\hline$p$ & 0.009 & 0.468 & 0.017 & 0.841 \\
\hline$n$ & 18 & 34 & 8 & 44 \\
\hline
\end{tabular}

\section{Conclusions}

We have continued the investigation of earlier discovered joint acoustic and electric responses of the near-surface sedimentary rocks on the deformation by earthquake seismic waves. Occurrences and absence of such responses for 52 earthquakes with the energy class of more than 11.0 were considered. These events which took place from June 2017 to May 2021 by the eastern coast of South Kamchatka. We discovered the statistically significant relation between the energy class of the earthquakes, during which joint seismoacoustic and seismoelectric responses of rocks were observed, and between the distance from hypocenter to the observation site. Such a relation was discovered for rock acoustic response on seismic waves from the earthquakes, during which besides the low-frequency cluster of about up to $100 \mathrm{~Hz}$, the cluster at the frequencies of $\sim 0.1-1 \mathrm{kHz}$ and even higher-frequency cluster at the frequencies of $\sim 1-11 \mathrm{kHz}$ were also observed. These clusters are likely to be generated by rocks during intensive deformations, formation of relative microdisplacements and interaction of small fragments. When there was no seismoelectric response of rocks and only low-frequency cluster was presented in the seismoacoustic response, we did not detect any statistically significant relation between earthquake energy class and distance from hypocenter.

The work was carried out within the framework of the State Task AAAA-A21121011290003-0. We applied the data, obtained at a unique scientific unit "Seismo-infrasonic complex to monitor arctic cryolithic zone and a complex for continuous seismic monitoring of the Russian Federation, cross-border regions and the world“" (https://ckp-rf.ru/usu/507436/).

\section{References}

[1] I.G. Kissin, Fluids in the earth's crust: Geophysical and tectonic aspects (Moscow, Nauka, 2015) 328

[2] A.G. Ivanov, Proceedings of the Academy of Sciences of the USSR, a series of geographical and geophysical, 5, 18-21 (1940)

[3] Yu.V. Marapulets, B.M. Shevtsov, Mesoscale acoustic emission (Vladivostok, Dal'nauka, 2012) 126

[4] P.V. Muratov, O.P. Rulenko, Yu.V. Marapulets, A.A. Solodchuk, Bulletin KRASEC. Physical \& Mathematical Sciences, 5(25), 62-73 (2018)

[5] P.V. Muratov, O.P. Rulenko, Yu.V. Marapulets, E3S Web of Conferences, 127 (02015), (2019)

[6] M.A. Mishchenko, O.P. Rulenko, Yu.V. Marapulets, E3S Web of Conferences, 196 (02028), (2020) 
[7] A.V. Kuptsov, I.A. Larionov, B.M. Shevtsov, Volcanology and Seismology, 5, 45-59 (2005)

[8] V. Borovikov, STATISTICA. The Art of Computerized Data Analysis: For Professionals (St. Petersburg, Piter, 2003) 688 